\title{
Patterns in abdominal pumping, miniature inspirations and heartbeats simultaneously recorded during cyclical gas exchange in adult Hylobius abietis (Coleoptera: Curculionidae) using a respirometer and IR actographs
}

\author{
Ivar SIBUL ${ }^{1}$, AARE KUUSIK $^{2}$ and KaLJo VOOLMA ${ }^{3}$ \\ ${ }^{1}$ Faculty of Forestry, Estonian Agricultural University, Kreutzwaldi 5, EE51014 Tartu, Estonia; e-mail: isibul@eau.ee \\ ${ }^{2}$ Institute of Plant Protection, Estonian Agricultural University, Kreutzwaldi 64, EE51014 Tartu, Estonia \\ ${ }^{3}$ Forest Research Institute, Estonian Agricultural University, Kreutzwaldi 5, EE51014 Tartu, Estonia
}

Key words. Abdominal pumping, CFV and CFO cycles, discontinuous gas exchange cycles, active ventilation, respiration, heartbeats, Hylobius abietis, Curculionidae

\begin{abstract}
Rhythms in abdominal pumping, heartbeats and discontinuous gas exchange cycles (DGCs) of CFV subtype (closed, flutter and ventilation periods) in adults of pine weevil Hylobius abietis were simultaneously recorded using an electrolytic microrespirometer and an infrared (IR) cardiograph or IR actograph (IRA). The cyclic release of carbon dioxide was associated with active ventilation ( $\mathrm{V}$ phase) provided by vigorous abdominal pumping movements due to contractions of tonic longitudinal and transversal abdominal muscles, which are visible to the naked eye. On the IRA-recordings, the abdominal pumping signals are superimposed on the heartbeat spikes. The relative amplitude of the abdominal pumping signals on these recordings is more than 10 times greater than that of the heart beats. Visual observations showed that the subelytral cavity appeared to be closed during the release of carbon dioxide and open at other times. The flutter (F) of the CFV cycle is characterised by active miniature inspirations or ventilations before the $\mathrm{V}$ period. The miniature ventilation movements were imperceptible to the naked eye, but were recorded on the respirometer-actigraph as clear spikes. In addition, movements of the tip of the abdomen, of between 10-20 $\mu \mathrm{m}$ were seen under a stereomicroscope at a magnification of $40 \times$. Some cycles were categorized as (C)FV cycles, when the $\mathrm{C}$ period disappears into the end of the $\mathrm{V}$ period. Abdominal pumping and miniature inspirations were clearly synchronized with the CFV cycles. Abdominal pumping movements, miniature inspirations or ventilations and heartbeats in adult $H$. abietis were distinguishable when recordings of the electrolytic microrespirometer-actograph and IRA were made in parallel. These three events were recognized by their different amplitudes and frequencies. It is presumed that abdominal pumping and miniature inspirations in adult $H$. abietis are obligatory rhythmic movements of different function and origin.
\end{abstract}

\section{INTRODUCTION}

In many insects, including adult beetles, discontinuous gas exchange cycles, or DGCs, have been investigated in detail. There are two subtypes of DGC or CFB (closed, flutter, burst) respiration: CFO (closed, flutter, open) and CFV (closed, flutter, ventilation) cycles. In discontinuous gas exchange carbon dioxide is released cyclically, and oxygen uptake often occurs periodically (for reviews about DGCs see Miller, 1974; Kestler, 1985; Sláma, 1988; Lighton, 1994, 1996; Tartes, 1995; Wasserthal, 1996; Harrison, 1997). DGCs are usually studied by flowthrough respirometry, using infrared gas analysers, which do not record ventilation movements and air inflow into the tracheae. However, Kestler (1971) showed by simultaneous microscopical observation and flow-through DIRGA respirometry that spiracular opening and pumping during CFV cycles can be recorded. A highresolution flow-through respirometry system was designed by Lighton (1990, 1991). Miniature ventilation movements, interpreted as extracardiac haemolymph pressure pulsations (EHP), can be recorded from an insect's body surface (Sláma, 1984, 2000).

An additional device is needed for simultaneous recording of DGCs and body movements. Therefore, the body movements involved in the respiration of beetles have been little studied. Abdominal ventilation movements, usually referred to as abdominal pumping, are characteristic of some adult beetles. These movements can be seen with the naked eye. Abdominal pumping in Coleoptera is caused by dorsoventral muscles along with tonic longitudinal and transverse holding muscles (Miller, 1974, 1981; Mill, 1985). In some beetles the abdominal air sacs are inflated by the active depression of the tergites, which are kept in an inspiration position by elastic resilin ribs (see Wasserthal, 1996).

In several insects there are CFV cycles, in which discontinuous releases of carbon dioxide are accompanied by abdominal pumping. Kestler (1971) detected CFV cycles in Periplaneta americana, Blaberus sp. and Carabus coriaceus. In the adult tok-tok beetle, Psammodes striatus, CFV cycles, i.e. abdominal pumping, occurs during DGC when carbon dioxide is released (Lighton, 1988). Desert tenebrionid beetles display a DGC pattern, in which "abdominal pulsation" occurs in the release period (Lighton, 1991). Some desert carabid beetles exhibit spiracular movements or muscular pumping in the release period. At the lowest oxygen concentrations, active ventilation through muscular contractions is required to ensure that the metabolic demand for 
oxygen can be met in the adult scarabeid beetle, Aphodius fossor (Chown \& Holter, 2000).

Another type of obligatory body movements are the miniature inspirations or ventilations recorded in the $\mathrm{F}$ period, which are characterized by regular $\mathrm{CO}_{2}$ release. The underlying suction ventilation was recorded first by Hustert (1975) in myograms of the abdominal inspiratory muscles of locusts.

The aim of the present paper was to study several patterns and types of abdominal movements in adult Hylobius abietis. A special task was to determine how these movements are coordinated with the gas exchange cycles.

\section{MATERIAL AND METHODS}

\section{Insects}

For experiments, adults of $\mathrm{H}$. abietis were collected during May and June 2002 from pitfall traps in a recently clear-felled area in the forest district of Räpina, Southern Estonia $\left(58^{\circ} 09^{\prime} \mathrm{N}\right.$, $27^{\circ} 08^{\prime} \mathrm{E}$ ), where H. abietis was abundant (Sibul, 2000). Weevils were stored in one-litre glass containers with food (Scots pine twigs) at $2-3^{\circ} \mathrm{C}$. Prior to the experiments, these beetles were transferred to ambient laboratory conditions for 2 days, where they were not fed. The body mass of the weevils used in the experiments ranged from 120 to $230 \mathrm{mg}$ (mean $183 \pm 22 \mathrm{mg}$ ).

\section{Electrolytic respirometer}

A differential electrolytic microrespirometer was used to record oxygen uptake, discontinuous gas exchange rhythms and body movements (Tartes \& Kuusik, 1994; Kuusik et al., 1996, 2001; Tartes et al., 1999, 2000, 2002). The respirograms display the rates of electrolytic generation of oxygen, which are indicated on the graphs as $\mathrm{FO}_{2}\left(\mathrm{ml} \mathrm{h}^{-1}\right)$. The measurements were computerized using an analog-to-digital converter (DAS 1401, Keithley-Metrabyte). The mean metabolic rates (oxygen consumption) were calculated by averaging the data over a period of at least $10 \mathrm{CFB}$ cycles. The respirometer recorded the air pressure changes in the insect chamber, caused by the body volume changes due to the irregular pumping movements of the insect (Figs 1,2). The release of carbon dioxide resulted in characteristic troughs in the recording lasting several minutes (Figs $3,5,8)$. By injecting different volumes of $\mathrm{CO}_{2}$ into the respirometer to simulate the $\mathrm{CO}_{2}$ release, it was possible to show that the peak $\mathrm{E}$ that appears shortly after the peak in $\mathrm{CO}_{2}$ (Figs 3, 5, 6,8 ) is not an artefact but caused by a decrease in insect body volume. The volumes of the single miniature inspirations in Fig. 4 were calibrated (volume $\mathrm{ml}$ ) by simulating the inspirations using an air-tight syringe $(1 \mathrm{ml})$.

The insect chamber was an Eppendorf conical test tube (volume $1.5 \mathrm{ml}$ ). In the conical part of the test tube, the beetle was restrained in a motionless posture. The respirograms indicated whether the beetle was struggling (escape behaviour and irregular pumping movements) or motionless (see Figs 1, 3, 8). As many adults of $H$. abietis were highly active in the insect chamber for many hours at room temperature a mechanical stimulus - shaking of the insect chamber - was used to induce them to become immobile (see Metspalu et al., 2002).

\section{Infrared actograph}

The respirometer was combined with a two-channel infrared actograph (IRA) with two IR-emitting diodes (TSA6203) and two IR-sensor diodes (BP104), which were placed on the sides of the insect chamber (for the IR cardiograph see Hetz, 1994; Wasserthal, 1996; Hetz et al., 1999). As well as heart beats the IRA recorded abdominal pumping, caused by vigorous contractions of the abdominal muscles (see Metspalu et al., 2001, 2002) and miniature inspirations, which caused a slight modulation of the heartbeat signals (Fig. 4).

\section{Statistics}

All means are reported with standard deviation (SD) and sample size (n). Sample size indicated in the text either represents number of beetles used or, in the case of cyclic gas exchange, at least ten cycles per beetle. Analysis of variance (ANOVA) was used to compare data. The significance level was set at $\mathrm{P} \leq 0.05$.

\section{RESULTS}

\section{Abdominal pumping}

Apparently motionless beetles displayed either continuous pumping movements (Fig. 1), or pumping movements that occurred only during carbon dioxide release

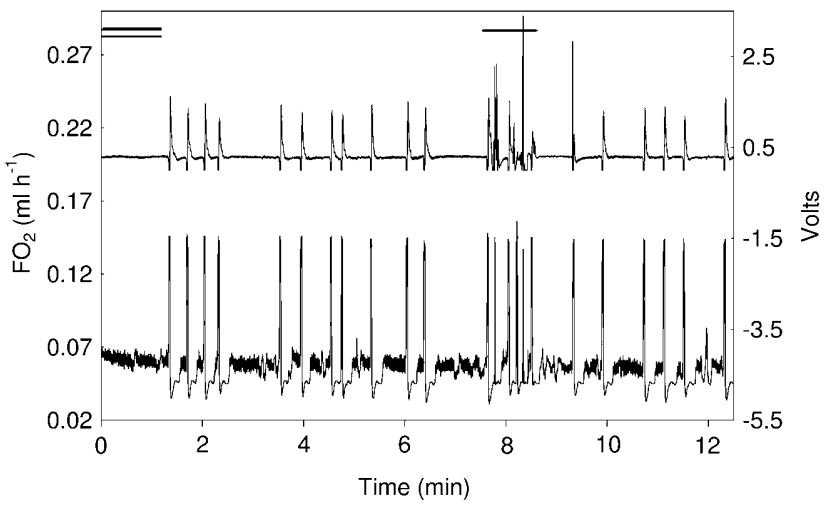

Fig. 1. An IRA recording (upper trace, Volts) and a simultaneously recorded respirogram obtained using an electrolytic respirometer (lower trace, $\mathrm{FO}_{2}$ ). Horizontal bar indicates when the beetle struggled. Double bar indicates the section shown in detail in Fig. 2. In this recording the pumping that causes continuous irregular ventilation start with convection $\mathrm{O}_{2}$ uptake during inspiration and a longer $\mathrm{CO}_{2}$ release is superimposed on the heartbeats of the adult Hylobius abietis (205 mg).

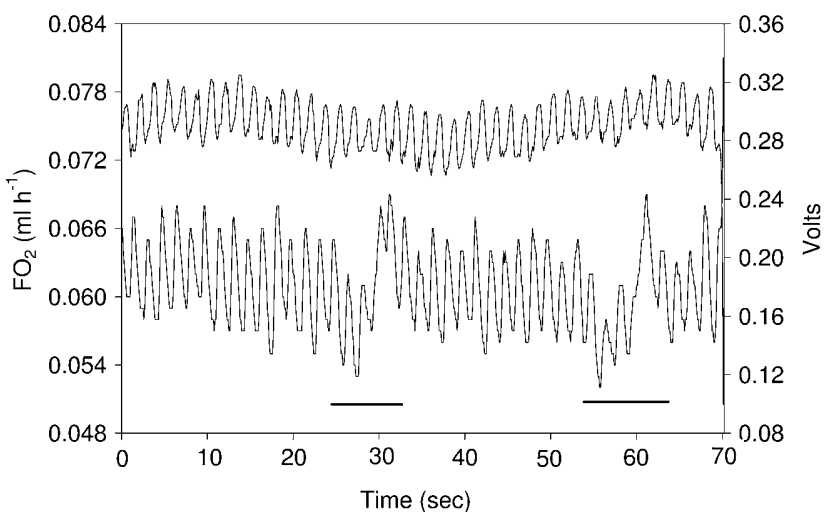

Fig. 2. A high resolution simultaneous recording of a section of Fig. 1 (double bar) in which the heartbeats and two microcycles (horizontal bars) are superimposed. The two strokes show a fast $\mathrm{O}_{2}$ uptake and a slow decrease in the microcycles of microopening and micro-closing $\left(\mathrm{FO}_{2}\right)$. The upper trace is a simultaneous IRA recording (Volts).

(Figs 3, 5). Continuous pumping movements are a sign of a stress, and after 2-3 h most beetles changed to discontinuous movements accompanying the cyclic release of carbon dioxide. Visual observation of beetles that had 


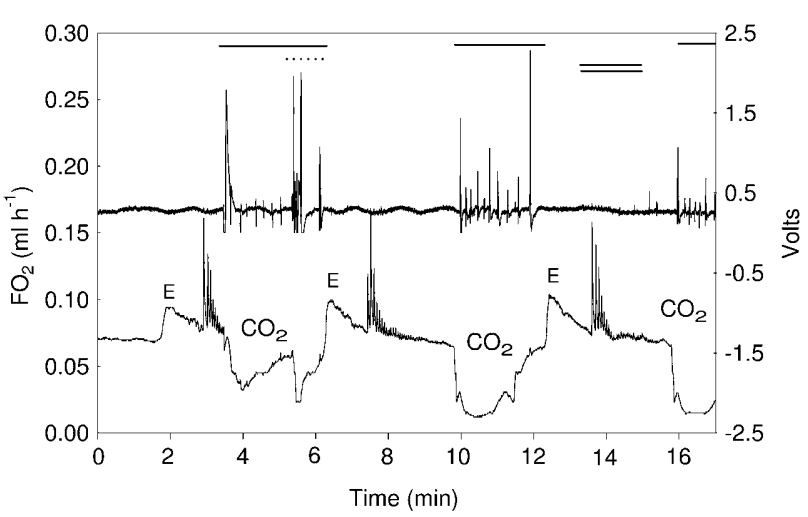

Fig. 3. Bouts of abdominal pumping recorded on an IRA (horizontal bars, upper trace, Volts). The pumping is synchronized with the release of $\mathrm{CO}_{2}$ recorded on the respirogram (lower trace, $\mathrm{FO}_{2}$ ). The trace from the last pumping movement to $\mathrm{E}$ records a decrease in tracheal volume in the $\mathrm{C}$ period. $\mathrm{E}$ indicates the start of a corresponding increase in volume in the $\mathrm{F}$ period (lower trace). In the middle of both $\mathrm{F}$ periods a bout of miniature inspirations occurs at the end of the pressure increase. The dotted line indicates intracyclic activity (INCA): leg or antennal movements. A minor INCA occurs in both traces during the second release of $\mathrm{CO}_{2}$. Double horizontal bar indicates the fragment of this trace shown in detail in Fig. 4.

their wings and elytra cut off showed that the pumping movement was a complex vigorous abdominal contraction involving several tergosternal and longitudinal muscles. Pumping occurs during carbon dioxide release as shown in Figs 3 and 5. On the IRA recording, the abdominal pumping movements are synchronized with the heartbeats but with peaks of about 10 times higher amplitude and with significantly lower frequencies (Fig. 6). The pumping and heartbeat frequencies were different: $4.75 \pm 0.96$ (range 4.2-7.1) and 36.7 \pm 1.81 (range 33-41) per min, respectively (ANOVA, $\mathrm{F}=1297, \mathrm{P}=$ $0.00, \mathrm{n}=5)$.

\section{Miniature inspirations or ventilations}

Miniature abdominal inspirations or ventilations were not observed in beetles from which the wings were removed, even under a stereomicroscope at a magnification of $20 \times$. However, when viewed at a magnification of

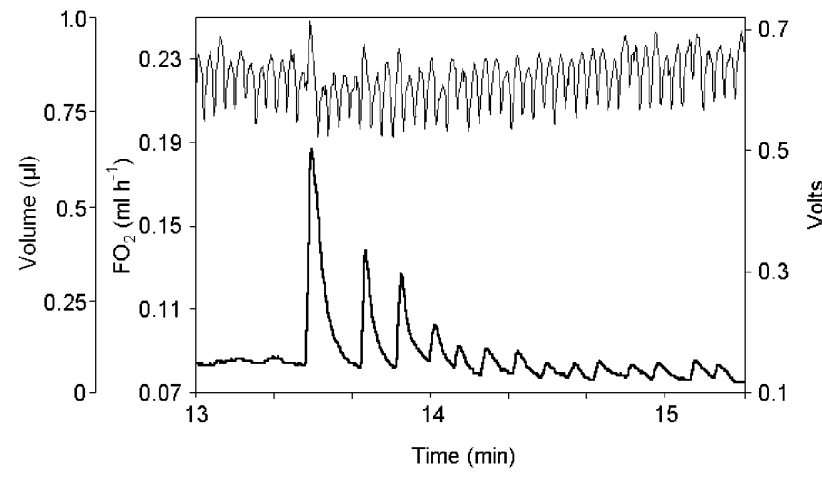

Fig. 4. A high resolution recording of a section of Fig. 3 (double bar) showing that heartbeats (upper trace, Volts) are only slightly modulated by the miniature inspirations recorded on the lower trace $\left(\mathrm{FO}_{2}\right)$.

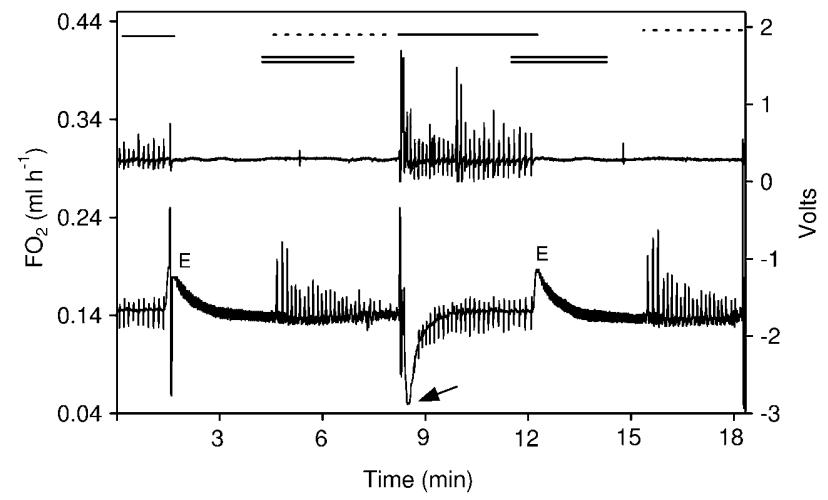

Fig. 5. An IRA recording (upper trace,Volts) and a simultaneous respirogram (lower trace, $\mathrm{VO}_{2}$ ) of $\mathrm{CFV}$ cycles. The release of $\mathrm{CO}_{2}$ lasts for as long as the pumping (V), which shows a typical exponential fall in the negative record of $\mathrm{CO}_{2}$ release during ventilation $\mathrm{V}$ (solid bars). The arrow marks the maximum release of $\mathrm{CO}_{2}$. The $\mathrm{C}$ period starts at the end of the $\mathrm{V}$ period and lasts until E. Miniature inspirations (dotted lines) occur after the pressure rise (E) in the steady state $\mathrm{F}$ and end with the start of V. Adult $H$. abietis of body mass $258 \mathrm{mg}$. Right and left double bars indicate the regions shown in detail in Fig. 6 and Fig. 7, respectively.

$40 \times$ the tip of the abdomen of intact beetles moved with an amplitude of 10-20 $\mathrm{mm}$. On the respirograms, miniature inspirations or ventilations, indicated by the sawtooth pattern, appeared within 2-3 min of the end of carbon dioxide release, while miniature inspirations could not be detected on the IRA recordings (Figs 3, 5). However, the first 2-3 large inspirations caused a weak modulation in the heartbeat signals in high resolution IRA recordings (Fig. 4).

Before miniature inspirations there is always a characteristic peak in the respirogram, which indicates a pressure increase followed by decrease, denoted by the letter E (Figs 3, 5, 6, 8), and marks the transition from the $\mathrm{C}$ (losed) to $\mathrm{F}$ (lutter) phase. Some minutes after $\mathrm{E}$ the saw-tooth pattern indicates microopenings (miniature inspirations) and closures of the spiracles, which may

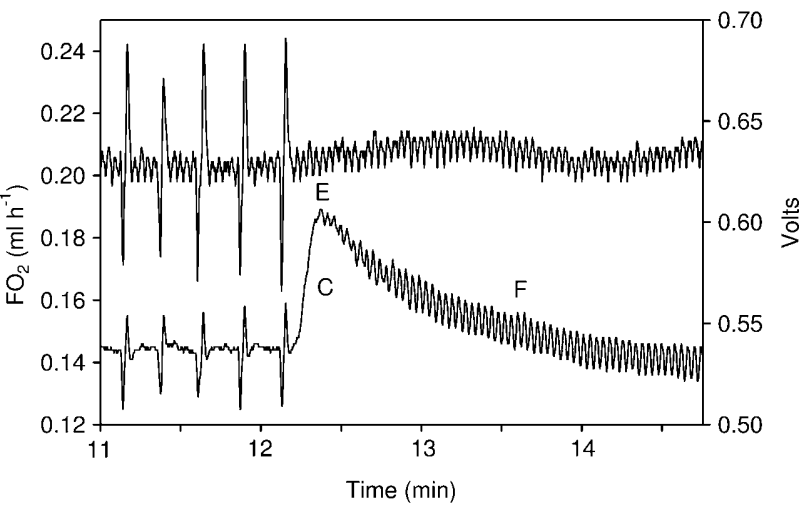

Fig. 6. A high resolution recording of a section from Fig. 5 (right double bar) showing the abdominal pumping movements (large spikes) and heartbeats. At the end of $\mathrm{C}$ (point E) and the start of F the SEC opens and heartbeats appear on the respirogram. Note the exact synchrony of the spikes (heartbeats) in the upper and lower traces. 


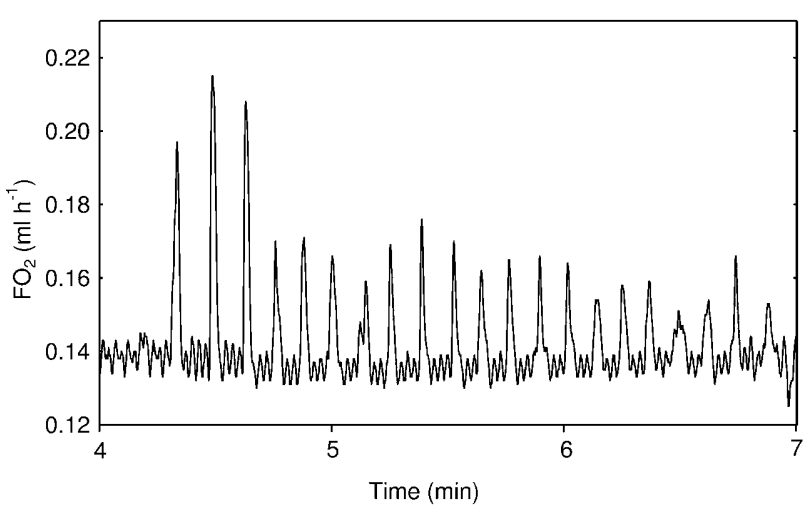

Fig. 7. A high resolution recording of the respirogram from Fig. 5 (left double bar) showing that the large spikes due to miniature inspirations are superimposed on the more frequent and smaller spikes due to heart beats.

lead to a pulsating inspiration in the subelytral cavity (SEC) in the F period. It is possible that the relatively high first spikes (see Figs 3-5) are due to the first miniature inspirations and active convective uptake of oxygen and the slow volume increase after $\mathrm{E}$ to a more continuous diffusive-convective leakiness due to fluttering (nanocycles). Beetles in which the first abdominal spiracle was cannulated displayed only the saw-tooth pattern of pulsations (inspirations). The mean frequencies of the first three large inspirations and the following small ones were $9.4 \pm 1.6$ (range 5-12) and $14.9 \pm 1.19$ (range 13-17) per min, respectively. Thus the frequencies of the weak inspirations (14.9 per min) and heartbeats (36.7 per min) were different (ANOVA, $\mathrm{F}=129.7, \mathrm{P}=0.00, \mathrm{n}=$ 8).

During the initial uninterrupted continuous but irregular pumping, the heartbeat signals on the respirograms were modulated by very weak abdominal movements due to irregular microopenings of the microcycles or passive suction ventilation (PSV) (Figs 1, 2). However, the frequency of these abdominal pulses was much lower

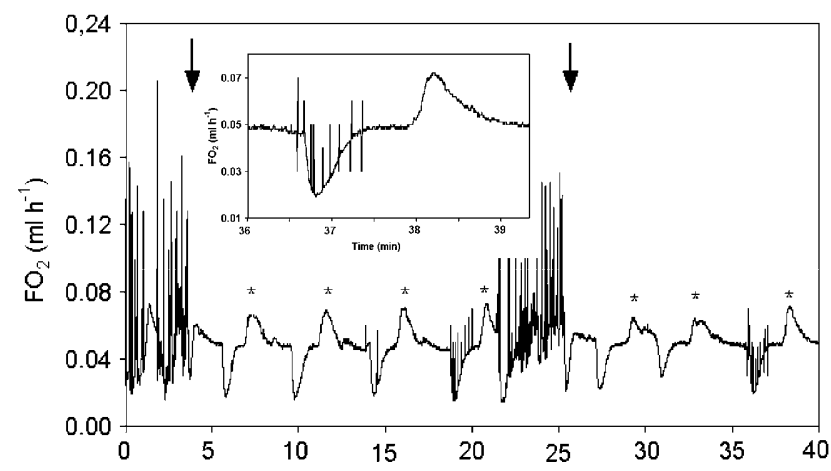

Fig. 8. Two periods of struggling ended when the beetle was immobilized by shaking the insect chamber (arrows). Note that the first of the two releases of $\mathrm{CO}_{2}$ is not associated with abdominal pumping (CFO cycles), suggesting the beetle was then feigning death. Ventilation movements occurred during subsequent $\mathrm{CO}_{2}$ release indicating that the beetle was no longer feigning death. The asterisks mark point $\mathrm{E}$, the transition from the $\mathrm{C}$ to the $\mathrm{F}$ period. The insert is a high resolution recording of the last $\mathrm{CO}_{2}$ release ( $\mathrm{CFV}$ cycle).

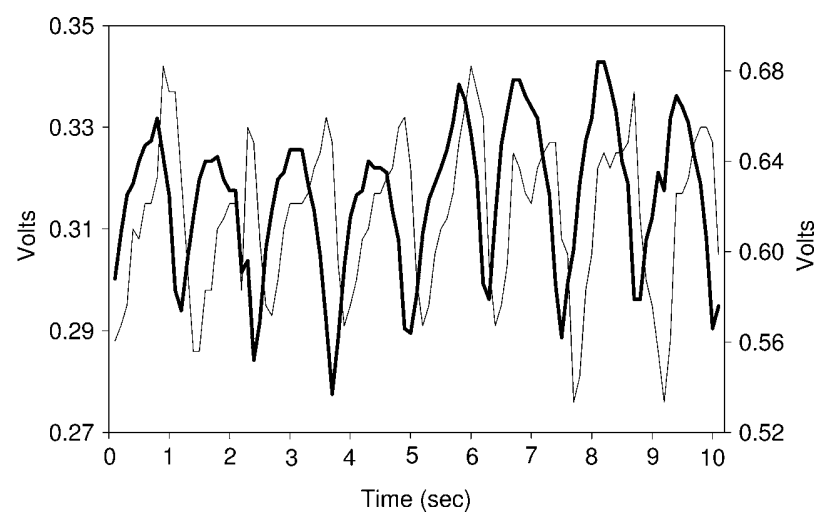

Fig. 9. Simultaneous recordings of a two-channel IRA, with one IR-sensitive diode on the first abdominal segment (thin trace, left axis) and the other on the fourth segment (thick trace, right axis), indicating that adult Hylobius abietis show anterograde heartbeats during the period between releases of $\mathrm{CO}_{2}$.

(1.77 \pm 0.15 per $\mathrm{min})$ than during discontinuous gas exchange (14.9 \pm 1.19 per $\mathrm{min}$ ) (ANOVA, $\mathrm{F}=1874, \mathrm{p}=$ $0.00, \mathrm{n}=5$ individuals). Moreover, the intervals between these pulses during continuous pumping were rather irregular.

\section{Abdominal pumping and miniature ventilations or inspirations in CFV cycles}

The discontinuous gas exchange cycle showed some characteristic events when an IRA recording was made simultaneously with a respirogram (Figs 1-6). Release of carbon dioxide, when accompanied by abdominal pumping, lasted $1.93 \pm 0.48 \mathrm{~min}$ (range 1.2-2.8 min). Pumping always stopped when a slow abdominal contraction occurred in parallel with the lowering of the last abdominal segments, which we interpret as the opening of the SEC (Figs 3, 5, 6, 8, denoted with E). The $\mathrm{C}$ period lasts from the last pumping stroke (Fig. 6) to the point $\mathrm{E}$ when the F period starts with the lowering of tip of the abdomen. The subsequent pressure rise leads to a volume increase and miniature inspirations occur as shown in Fig. 3 and Fig. 5 in the last part of the F period.

Thus, each release of carbon dioxide was preceded by many miniature inspirations lasting $4.28 \pm 0.98 \mathrm{~min}$ (range 3.4-5.9 $\mathrm{min}$ ). It was not possible to establish if the miniature inspirations occurred during the release or not with the method used, however, no inspiration movements were recorded during the following 2-3 min (Figs 3, 5). Our observations showed that the last abdominal segments were pressed against the elytra, i.e. the SEC seems to be closed during the release of carbon dioxide and open at the beginning of the increase in compression of the abdomen (E). Thus both miniature inspirations and the pumping movements are synchronized with the CFV cycles.

\section{Immobility evoked by mechanical stimulus}

In the insect chamber some beetles that were not restrained (about 20\%) showed continuous irregular pumping movements alternating with periods when they struggled (escape behaviour). In this case immobility of 
the beetles was evoked by a mechanical stimulus: weak tapping on the insect chamber. After this stimulus the struggling momentarily stopped and CFO cycles appeared, i.e. gas exchange cycles not associated with pumping movements (Fig. 8). After 2-3 CFO cycles active ventilation was recorded during the $\mathrm{CO}_{2}$ release, which means that the $\mathrm{CFO}$ cycles changed into $\mathrm{CFV}$ cycles (Fig. 8 insert). The induced immobility lasted 10-20 min after which the beetles resumed struggling. However, the induced periods of immobility gradually shortened, suggesting the beetles became habituated to the shock. In some beetles the struggling changed into continuous abdominal pumping without gas exchange.

\section{Recording of heartbeats by means of an electrolytic respirometer and IRA}

The respirograms of large beetles weighing over 200 mg showed clear heartbeat rhythms (Figs 5-7). The heartbeats could be seen as rhythmic movements of the medial part of the tergites of beetles, which had their wings and elytra cut off, when observed from the side under a stereomicroscope. The amplitude of the movements of the tergites $(20-30 \mathrm{~mm})$ was sufficient to cause air pressure changes in the insect chamber of the respirometer. In Fig. 7 the miniature inspirations, superimposed on the heartbeats, are obvious, while in Figs 2 and 6 the heartbeat spikes on the IRA recording and the spikes on the respirogram are synchronized. Peristalsis of the dorsal vessel was forwards directed (anterograde heartbeats) both at the time of the release and during the interrelease periods (see Fig. 9).

It was remarkable that the heartbeat signals only appeared on the respirograms after point E (Figs 5,6), which as stated above records an inspiration into the abdominal spiracles and the SEC, but this is masked by the concomitant volume increase. This inspiration movement was made at the time of the supposed opening of the SEC. During continuous pumping, occurring without DGCs, hearbeats were also recorded on the respirograms (Figs 1, 2), when visual observation indicated the subelytral cavity was open.

We suggest that the tergite movements due to the heartbeats, causing the volume changes in the respirometer, are also involved to some extent in the ventilation of the SEC.

\section{DISCUSSION}

During the first 2-3 h adults of $H$. abietis displayed continuous irregular pumping movements without release of carbon dioxide, i.e. without gas exchange cycles (Figs $1,2)$. However, later on regular CFV cycles appeared and abdominal pumping was accompanied by release of $\mathrm{CO}_{2}$. Therefore, we suggest that continuous pumping is a sign of stress (see Möbius et al., 1996). According to Kestler (1991) several stress factors may cause respiratory failure.

From the middle of the $\mathrm{F}$ period until release (V period) regular miniature inspirations (microopening and closing of the spiracles) were recorded on the respirometeractograph. On the simultaneous IRA recording the heart- beat was slightly modulated by the first $2-3$ inspirations, but during subsequent inspirations no movements were recorded on the IRA (Fig. 4). The flutter period of the cyclic gas exchange was first described in silkworm (Hyalophora cecropia) pupae and is characterized by small movements of the spiracular valve: opening slightly for a few seconds and then closing (fluttering), with each opening accompanied by a stepwise increase in pressure towards atmospheric (Levy \& Schneiderman, 1966; Brockway \& Schneiderman, 1967; Kestler, 1985). A convective and quantized $\mathrm{F}$ phase ventilation occurs in locusts (Hustert, 1975) and desert tenebrionid beetles (Lighton, 1991; Duncan et al., 2002).

The results of the present study indicate that in adult $H$. abietis and many other beetle species, abdominal pumping and miniature inspirations are different types of rhythmic movements. During a release of carbon dioxide, abdominal pumping is observable, however during the second part of the $\mathrm{F}$ period there are miniature inspirations, which are almost invisible even when beetles are observed under a stereomicroscope. It is possible that miniature inspirations in adult $H$. abietis occurred also during release of carbon dioxide, however these inspiration movements were not detectable by the methods used. After each release a pause in inspirations occurred. Thus both the abdominal pumping and miniature inspirations were synchronized with the CFV cycles.

During stress, when cyclic gas exchange is absent, the passive tracheal pulsation of the microcycles of microopening and closing was recorded as volleys of diffusive and convective oxygen uptake between the abdominal pumping signals (Figs 1, 2). However, the intervals between passive suction ventilations (PSV) or microcycles were irregular and longer than those between miniature inspirations in the F period of the CFV cycles. Several stress factors, including chemical ones, evoke changes in the normal patterns of the EHP (Sláma \& Miller, 1987), which indicates that EHP and PSV in tethered or stressed insects are similar.

There were beetles that struggled, i.e. attempted to escape for many hours but could be induced to become immobile by a mechanical stimulus. Many insects, especially species of Coleoptera, respond to a sudden and brief mechanical stimulus by abruptly adopting a state of more or less complete tonic immobility. Such a pose, while retaining a foothold, has been termed death feigning (catalepsy) or tonic immobility (Richards, 1953). After shaking the beetles stopped struggling momentarily and $\mathrm{CFO}$ respiration started but no pumping movements were recorded, suggesting the beetles adopted a freezing pose. After a period of tonic immobility CFV cycles of respiration, characterized by abdominal pumping during the release of $\mathrm{CO}_{2}$, occured (Fig. 8). Thus the respirometer-actograph recordings showed when the beetles emerged from tonic immobility and entered a resting state. Immobility is induced by the same mechanical stimulus in adult Leptinotarsa decemlineata (Metspalu et al., 2002). 
During the $\mathrm{C}$ period the SEC was closed up to point $\mathrm{E}$ and air inflow (E) during the $\mathrm{F}$ period was maintained by miniature inspirations. Pulses of $\mathrm{O}_{2}$ uptake and subsequent $\mathrm{CO}_{2}$ release during $\mathrm{V}$ in Fig. 3 and Fig. 5 show that short $\mathrm{CO}_{2}$ and $\mathrm{O}_{2}$ pulses can be recorded with an electrolytic respirometer. Between the interburst pumping strokes there are ventilation pauses $(\mathrm{C}+\mathrm{F})$, when the SEC remained open, and there were miniature ventilations, i.e. weak inspiration movements. However, it is unknown whether there is miniature expiration or if it is generated passively by negative tracheal pressure.

Miniature inspirations and/or EHPs may be confused with heart pulses when they have similar or even the same frequency (Sláma, 2000). According to the data presented here, the heartbeat frequencies of adult $H$. abietis were always higher than those of the miniature inspirations. Obvious differences in the heartbeat patterns and those of the miniature inspirations are also observed in pupae of Leptinotarsa decemlineata (Tartes et al., 2000; Kuusik et al., 2001; Metspalu et al., 2001) and adults of the same species (Kuusik et al., 2001; Metspalu et al., 2002).

We did not find heartbeat reversals in adult $H$. abietis: dorsal vessel peristalsis was directed forwards (anterograde heartbeat) both during carbon dioxide release and in the interrelease periods. Heartbeat reversal is a regular event in adults of several species of Coleoptera (Wasserthal, 1996). In resting adults of some Coleoptera (Goliathus, Oryctes) the haemolymph oscillates between the anterior and posterior region of the body resulting from periodic reversals in heartbeat (Wasserthal, 1982).

Three events are simultaneously recorded when an electrolytic respirometer is used in combination with an IRA: abdominal pumping, miniature inspirations, and heartbeat. As these events have different amplitudes and frequencies in adult $H$. abietis, the signals cannot be confused. In large beetles, the heartbeats that occur after carbon dioxide release can also be recorded on respirograms.

ACKNOWLEDGEMENTS. We thank P. Kestler and an anonymus referee for numerous suggestions and comments on an earlier version of the manuscript. The study was partly supported by grants No. 4728 and No. 4993 from the Estonian Science Foundation.

\section{REFERENCES}

Brockway A. \& Schneiderman H.A. 1967: Strain gauge transducer studies on intratracheal pressure and pupal length during discontinuous respiration in diapausing silkworm pupae. J. Insect Physiol. 13: 1413-1451.

CHown S.L. \& Holter P. 2000: Discontinuous gas exchange cycles in Aphodius fossor (Scarabaeidae): a test of hypotheses concerning origins and mechanisms. J. Exp. Biol. 203: 397-403.

Duncan F.D., Krasnov B. \& McMaster M. 2002: Novel case of a tenebrionid beetle using discontinuous gas exchange cycle when hydrated. Physiol. Entomol. 27: 79-83.

HARRISON J.F. 1997: Ventilatory mechanism and control in grasshoppers. Am. Zool. 37: 73-81.

Hetz S.K. 1994: Untersuchungen zu Atmung, Kreislauf und Säure-Basen-Regulation an Puppen der tropischen Schmet- terlingsgattungen Ornithoptera, Troides und Attacus. Dissertation, University Erlangen-Nürnberg, 189 pp.

Hetz S.K., Psota E. \& Wasserthal L.T. 1999: Roles of aorta, ostia and tracheae in heartbeat and respiratory gas exchange in pupae of Troides rhadamantus Staudinger 1888 and Ornithoptera priamus L. 1758 (Lepidoptera, Papilionidae). Int. J. Insect Morphol. Embryol. 28: 131-144.

Hustert R. 1975: Neuromuscular co-ordination and proprioceptive control of rhythmical abdominal ventilation in intact Locusta migratoria migratorioides. J. Comp. Physiol. 97: 159-179.

Kestler P. 1971: Die diskontinuierliche Ventilation bei Periplaneta americana L. und anderen Insekten. Publ. Dissert., Julius-Maximilians-Universität Würzburg, 232 pp.

KESTLER P. 1985: Respiration and respiratory water loss. In K.H. Hoffmann (ed.): Environmental Physiology and Biochemistry of Insects. Springer, Berlin, Heidelberg, pp. 137-189.

Kestler P. 1991: Cyclic $\mathrm{CO}_{2}$ release as a physiological stress indicator in insects. Comp. Biochem. Physiol. (C) 100: 207-211.

Kuusik A., Harak M., Hiiesaar K., Metspalu L. \& Tartes U. 1996: Different types of external gas exchange found in pupae of greater wax moth Galleria mellonella (Lepidoptera: Pyralidae). Eur. J. Entomol. 98: 23-35.

KuUsik A., Tartes U., Vanatoa A., Metspalu L. \& Hitesaar K. 2001: Body stereotypic movements and their possible role as triggers of heart activity in pupae of Colorado potato beetle Leptinotarsa decemlineata (Say). Physiol. Entomol. 26: 158-164.

LeVy R.I. \& SchneIDERMan H.A. 1966: Discontinuous respiration in insects. IV. Changes in intratracheal pressure during the respiratory cycle of silkworm pupae. J. Insect Physiol. 12: 465-492.

Lighton J.B.R. 1990: Slow discontinuous ventilation in Namib Desert dune-sea ant Camponotus detritus (Hymenoptea: Formicidae). J. Exp. Biol. 151: 71-82.

Lighton J.R.B. 1988: Simultaneous measurement of oxygen uptake and carbon dioxide emission during discontinuous ventilation in the tok-tok beetle, Psammodes striatus. J. Insect Physiol. 34: 361-367.

Lighton J.B.R. 1991: Ventilation in Namib Desert tenebrionid beetles: mass scaling and evidence of a novel quantized flutter-phase. J. Exp. Biol. 159: 249-268.

Lighton J.B.R. 1994: Discontinuous ventilation in terrestrial insects. Physiol. Zool. 67: 142-162.

Lighton J.R.B. 1996: Discontinuous gas exchange in insects. Annu. Rev. Entomol. 41: 309-324.

Metspalu L., Kuusik A., Hitesaar K., Jöudu J., Tartes U. \& HARAK M. 2001: Simultaneous recording of gas exchange cyclicity, body movements and heartbeats in pupae of Leptinotarsa decemlineata Say made by infrared optical method. Norw. J. Entomol. 48: 91-96.

Metspalu L., Kuusik A., Hiiesaar K. \& Tartes U. 2002: Tonic immobility in adult Colorado potato beetle, Leptinotarsa decemlineata (Coleoptera: Chrysomelidae) evoked by mechanical and optical stimuli. Eur. J. Entomol. 99: 215-219.

MiLL P.J. 1985: Structure and physiology of the respiratory system. In Kerkut G.A. \& Gilbert L.J. (eds): Comprehensive Insect Physiology, Biochemistry and Pharmacology. Vol. 3. Pergamon, Oxford, pp. 517-593.

MilLER P.L. 1974: Respiration - aerial gas transport. In Rockstein M. (ed.): The Physiology of Insecta. Academic Press, New York, San Francisco, London, pp. 345-402.

MilLER P.L. 1981: Ventilation in active and inactive insects. In Herreid C.F. \& Fourtner C.R. (eds): Locomotion and Ener- 
getics in Arthropods. Plenum Press, New York, London, pp. 367-390.

Möbius P., Kestler P. \& Penzlin H. 1996: Studies on the function of octopamin in stress respond of Periplaneta americana L. Verh. Dt. Zool. Ges. 89: 69.

RichaRDS K. 1953: Reflex activity and ganglion function. In Roeder K.D. (ed.): Insect Physiology. John Wiley, New York, Chapman Hall, London, pp. 463-487.

SibUL I. 2000: Abundance and sex ratio of pine weevils Hylobius abietis and $\mathrm{H}$. pinastri (Coleoptera: Curculionidae) in pine clear-cuttings of different ages. Trans. Eston. Agric. Univ. 209: 186-189.

SLÁmA K. 1984: Recording of haemolymph pressure pulsations from the insect body surface. J. Comp. Physiol. 154: 635-643.

Sláma K. 1988: A new look at insect respiration. Biol. Bull. Mar. Biol. Lab. 175: 289-300.

SLÁmA K. 2000: Extracardiac versus cardiac haemocoelic pulsation in pupae of the mealworm (Tenebrio molitor L.). $J$. Insect Physiol. 46: 977-992.

SlÁma K. \& Miller T.A. 1987: Insecticide poisoning: disruption of a possible autonomic function in pupae of Tenebrio molitor. Pestic. Biochem. Physiol. 29: 25-34.
TARTes U. 1995: Respiration Rhythms in Insects. Dissert. Biol. Univ. Tartuensis 14, Tartu, $110 \mathrm{pp}$.

Tartes U. \& KuUsiK A. 1994: Periodic muscular activity and its possible functions in pupae of Tenebrio molitor. Physiol. Entomol. 19: 216-222.

Tartes U., KuUsiK A. \& Vanatoa A. 1999: Diversity in gas exchange and muscular activity patterns in insects studied by a respirometer-actograph. Physiol. Entomol. 24: 150-157.

Tartes U., Kuusik A., Hiiesaar K., Metspalu L. \& Vanatoa A. 2000: Abdominal movements, heartbeats and gas exchange in pupae of the Colorado potato beetle, Leptinotarsa decemlineata. Physiol. Entomol. 25: 151-158.

Tartes U., Vanatoa A. \& KuUsiK A. 2002: The insect abdomen - a heartbeat manager in insects? Comp. Biochem. Physiol. (A) 133: 611-623.

WASSERTHAL L.T. 1982: Wechselseitige funktionelle und strukturelle Anpassungen von Kreislauf- und Tracheensystem bei adulten Insekten. Verh. Dt. Zool. Ges. 1982: 105-116.

WASSERTHAL L.T. 1996: Interaction of circulation and tracheal ventilation in holometabolous insects. Adv. Insect Physiol. 26: 297-351.

Received June 25, 2003; revised January 5, 2004; accepted February 10, 2004 